\title{
To Study the Immunological and Clinical Profile of Dengue Fever
}

\author{
Shilpa TA*, Dr. Nirmala AC
}

Department of Medicine, Bangalore Medical College and Research Institute, Bangalore, India

DOI: $10.36347 /$ sjams.2020.v08i05.030

| Received: 05.05.2020 | Accepted: 12.05.2020 | Published: 22.05.2020

*Corresponding author: Shilpa TA

\section{Abstract}

Original Research Article

Background: The incidence of dengue has grown dramatically across the world in the recent decade. According to World Health Organisation (WHO), about 50-100million new dengue infections are estimated to occur annually in more than 100 endemic countries, with a steady increase in the number of countries reporting the disease. This study describes clinical and immunological profile of dengue fever in patients admitted to the hospitals attached to Bangalore Medical College and Research Institute, Bangalore. Materials and methods: This is a retrospective study including 200 patients of dengue fever from November 2017 to April 2018. Results: Amongst 200 patients, who presented with dengue fever, $58.5 \%$ were males and $41.5 \%$ were females. About $37 \%$ were in the age group of 21 to 30 years with mean age of study group being $33.7 \pm 12.1$ years. All of them $(100 \%)$ had fever at the time of presentation followed by generalised bodyache(). $13.5 \%$ of them had hypotension. They were treated accordingly. This study showed NS1 positivity had significant association between platelet transfusion, bleeding manifestations and raised ALT levels. Our study showed mortality rate of 3\% for dengue fever. Conclusions: Early diagnosis and timely intervention are needed to prevent life threatening complications.

Keywords: World Health Organisation, generalized, Dengue Fever.

Copyright @ 2020: This is an open-access article distributed under the terms of the Creative Commons Attribution license which permits unrestricted use, distribution, and reproduction in any medium for non-commercial use (NonCommercial, or CC-BY-NC) provided the original author and source are credited.

\section{INTRODUCTION}

Dengue is the most rapidly spreading mosquito-borne viral infection of mankind, with a 30 fold increase in global incidence in the last decade [1].

Dengue virus was isolated in India for the first time in 1945. The first evidence of occurrence of dengue fever in the country was reported in 1956 from Vellore district in Tamil Nadu. The first Dengue hemorrhagic fever (DHF) outbreak occurred in Calcutta (West Bengal) in 1963[1].

Dengue is a mosquito-borne disease, caused by serologically related but antigenically distinct singlestrand positive sense RNA viruses. The viruses have been grouped into four serotypes (DENV-1 through DENV-4) belonging to the genus Flavivirus (family Flaviviridae). Aedes aegypti is the primary mosquito vector. However, other species from the genus Aedes such as Aedes albopictus can also be vectors of dengue virus transmission.

Previously classified as dengue fever (DF), dengue hemorrhagic fever (DHF) and dengue shock syndrome (DSS), currently according to the WHO dengue classification 2009, dengue is classified as dengue fever with or without warning signs and severe dengue [2].

Usually with the initial symptoms of dengue patients can't be differentiated into mild and severe form of dengue fever. Later as the disease progresses and they develop complications and with laboratory reports, it can be differentiated.

Generally, a dengue virus (DENV) infected person may be asymptomatic or may just develop undifferentiated fever, typically with rashes, body aches and pains, nausea, vomiting and diarrhea. This patient may then recover or may further deteriorate and develop warning signs which include persistent vomiting, abdominal pain and tenderness, bleeding tendencies, fluid accumulation, hepatomegaly, with increased hematocrits and decreased platelets. In this critical phase, if not clinically well-managed, severe plasma leakage, bleeding and organ impairment may occur and can be fatal [2].

Laboratory diagnosis of dengue is made by detecting the virus and/or any of its components (infective virus, virus genome, dengue antigen) or by investigating the serological responses present after infection (specifically IgM and IgG levels)[2]. 
There are studies reporting that thrombocytopenia,coagulopathy and vasculopathy are related to platelet and endothelial dysfunction in severe dengue.Some studies concluded that risk of developing DHF is more in patients with diabetes and hepatitis, also thrombocytopenia is more common in dengue patients who are NS1 positive[3,4].

Study done by Shiran Ajith Paranavitane et al., showed that NS1 positivity is associated with higher risk of developing severe dengue especially when positive beyond day 5 of illness [5].

\section{MeTHODS}

This is a retrospective study which included 200 patients of dengue fever from November 2017 to April 2018 in the hospitals attached to Bangalore Medical College and Research Institute, Bangalore, data based on the medical records of these hospitals.

\section{STATISTICAL ANALYSIS}

Data was entered into Microsoft excel data sheet and was analyzed using SPSS 22 version software. Categorical data was represented in the form of Frequencies and proportions. Chi-square test was used as test of significance for qualitative data. Continuous data was represented as mean and standard deviation.

\section{ResUlts}

Table-1: Age distribution of subjects

\begin{tabular}{|l|l|l|l|}
\hline \multicolumn{2}{|c|}{} & Count & $\%$ \\
\hline \multirow{5}{*}{ Age } & $<20$ years & 27 & $13.5 \%$ \\
\cline { 2 - 4 } & 21 to 30 years & 74 & $37.0 \%$ \\
\cline { 2 - 4 } & 31 to 40 years & 50 & $25.0 \%$ \\
\cline { 2 - 4 } & 41 to 50 years & 29 & $14.5 \%$ \\
\cline { 2 - 4 } & 51 to 60 years & 13 & $6.5 \%$ \\
\cline { 2 - 4 } & $>60$ years & 7 & $3.5 \%$ \\
\cline { 2 - 4 } & Total & 200 & $100.0 \%$ \\
\hline
\end{tabular}

In the study majority of subjects were in the age group 21 to 30 years $(37 \%), 25 \%$ were in the age group 31 to 40 years, $14.5 \%$ were in the age group 41 to 50 years, $13.5 \%$ were in the age group $<20$ years, $6.5 \%$ were in the age group 51 to 60 years and $3.5 \%$ were in the age group $>60$ years. Mean age of subjects was 33.7 \pm 12.1 years.

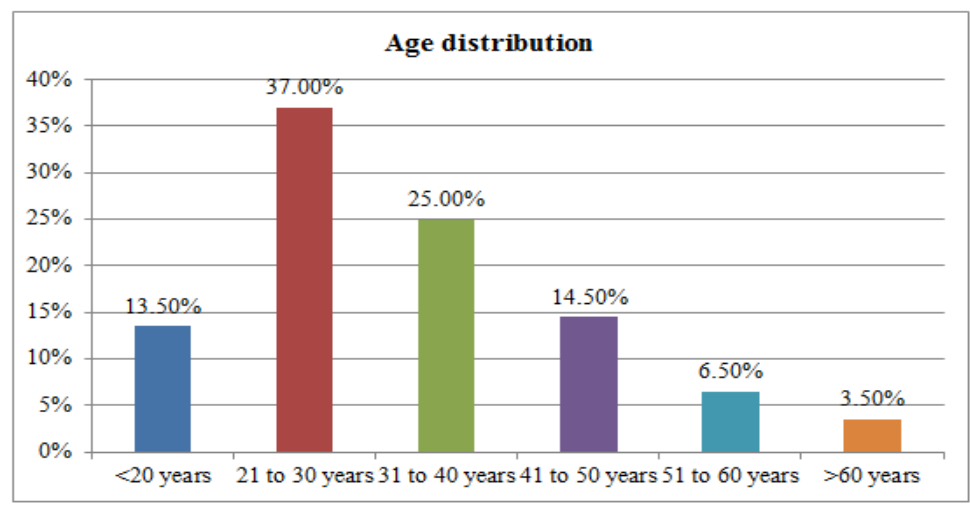

Fig-1: Bar diagram showing Age distribution of subjects

Table-2: Gender distribution of subjects

\begin{tabular}{|l|l|l|l|}
\hline \multicolumn{2}{|c|}{} & Count & $\%$ \\
\hline \multirow{3}{*}{ Gender } & Female & 83 & $41.5 \%$ \\
\cline { 2 - 4 } & Male & 117 & $58.5 \%$ \\
\cline { 2 - 4 } & Total & 200 & $100.0 \%$ \\
\hline
\end{tabular}

In the study $58.5 \%$ were males and $41.5 \%$ were females.

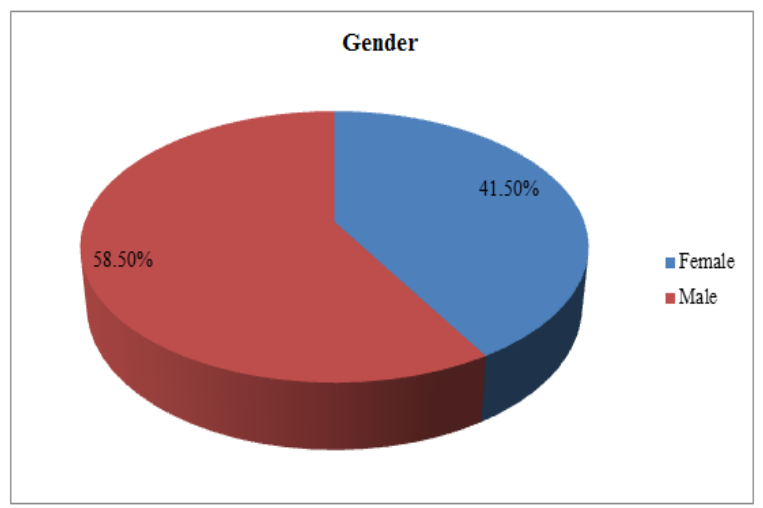

Fig-2: Pie diagram showing Gender distribution of subjects 
Table-3: Symptoms on presentation

\begin{tabular}{|c|c|c|c|c|}
\hline & \multicolumn{2}{|l|}{ Yes } & \multicolumn{2}{|l|}{ No } \\
\hline & Count & $\%$ & Count & $\%$ \\
\hline Fever & 200 & $100 \%$ & 0 & $0 \%$ \\
\hline Retro orbital pain & 28 & $14.0 \%$ & 172 & $86.0 \%$ \\
\hline Generalised body ache & 88 & $44.0 \%$ & 112 & $56.0 \%$ \\
\hline Arthralgia & 31 & $15.5 \%$ & 169 & $84.5 \%$ \\
\hline Skin rashes & 9 & $4.5 \%$ & 191 & $95.5 \%$ \\
\hline Vomiting & 48 & $24.0 \%$ & 152 & $76.0 \%$ \\
\hline Bleeding manifestations & 51 & $25.5 \%$ & 149 & $74.5 \%$ \\
\hline Abdominal pain & 13 & $6.5 \%$ & 187 & $93.5 \%$ \\
\hline Breathlessness & 5 & $2.5 \%$ & 195 & $97.5 \%$ \\
\hline Lethargy & 12 & $6.0 \%$ & 188 & $94.0 \%$ \\
\hline Seizures & 0 & $0 \%$ & 200 & $100 \%$ \\
\hline Altered sensorium & 0 & $0 \%$ & 200 & $100 \%$ \\
\hline
\end{tabular}

In the study $100 \%$ presented with fever, $14 \%$ had Retro orbital pain, $44 \%$ had generalised body ache, $15.5 \%$ had Arthralgia, $4.5 \%$ had skin rashes, $24 \%$ had
Vomiting, 25.5\% had Bleeding manifestations, $6.5 \%$ had abdominal pain, $2.5 \%$ had Breathlessness, $6 \%$ had Lethargy.

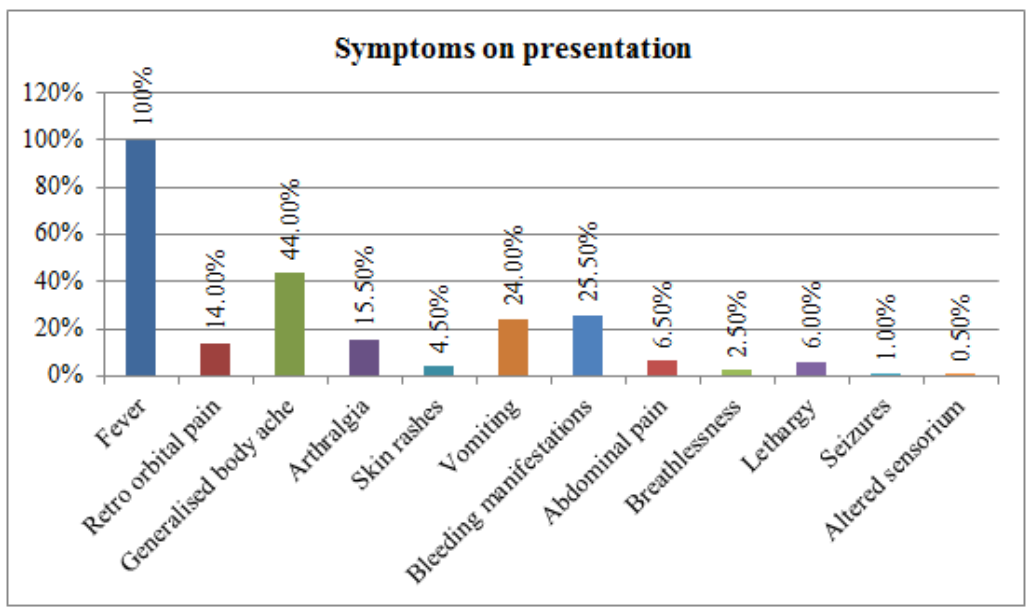

Fig-3: Bar diagram showing Symptoms on presentation

Table-3

\begin{tabular}{|l|l|l|l|}
\hline \multirow{3}{*}{ Others } & Cough & $\mathbf{1}$ & $\mathbf{0 . 5 \%}$ \\
\cline { 2 - 4 } & Loose stools & 2 & $1.0 \%$ \\
\cline { 2 - 4 } & No & 197 & $98.5 \%$ \\
\hline \multirow{3}{*}{ Hypotension } & Absent & 163 & $81.5 \%$ \\
\cline { 2 - 4 } & HTN & 10 & $5.0 \%$ \\
\cline { 2 - 4 } & Present & 27 & $13.5 \%$ \\
\hline \multirow{2}{*}{ Serosities } & Absent & 131 & $65.5 \%$ \\
\cline { 2 - 4 } & Present & 69 & $34.5 \%$ \\
\hline
\end{tabular}
Serosities.

In the study $1 \%$ had loose stools and $0.5 \%$ had cough, $13.5 \%$ had hypotension and $5 \%$ had HTN and $34.5 \%$ had

Table-4: Dengue serology findings distribution among subjects

\begin{tabular}{|l|l|l|l|l|}
\hline \multirow{2}{*}{} & \multicolumn{2}{|l|}{ Negative } & \multicolumn{2}{l|}{ Positive } \\
\cline { 2 - 5 } & Count & $\%$ & Count & $\%$ \\
\hline NS1 & 57 & $28.5 \%$ & 143 & $71.5 \%$ \\
\hline IgM & 143 & $71.5 \%$ & 57 & $28.5 \%$ \\
\hline IgG & 149 & $74.5 \%$ & 51 & $25.5 \%$ \\
\hline
\end{tabular}

In the study $71.5 \%$ were Positive for NS1, $28.5 \%$ were positive for IgM and $25.5 \%$ were positive for IgG. 


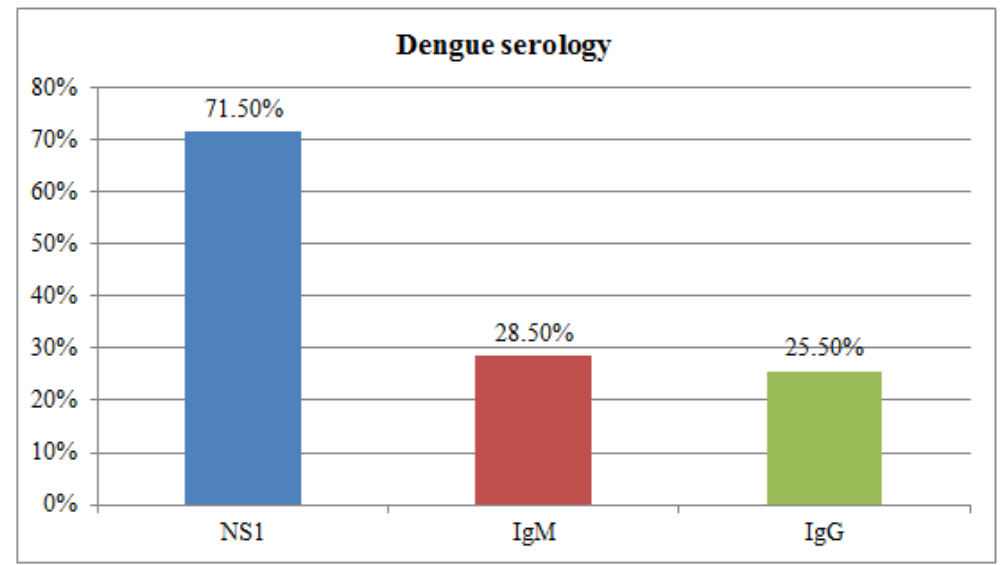

Fig-4: Bar diagram showing Dengue serology findings distribution among subjects

Table-5: Chest $\mathrm{X}$ ray findings distribution among subjects

\begin{tabular}{|l|l|l|l|}
\hline \multicolumn{2}{|c|}{} & Count & $\%$ \\
\hline \multirow{2}{*}{ Chest X ray } & Bilateral Effusion & 60 & $30.0 \%$ \\
\cline { 2 - 4 } & Normal & 140 & $70.0 \%$ \\
\hline
\end{tabular}

In the study $30 \%$ had Bilateral Effusion and $70 \%$ had normal Chest X ray.

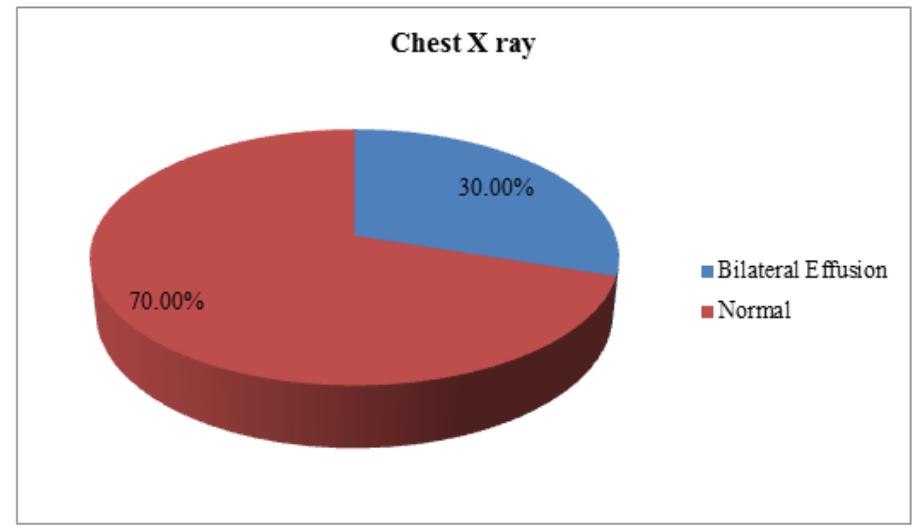

Fig-5: Pie diagram showing Chest $\mathrm{X}$ ray findings distribution among subject

Table-6: Outcome of patient distribution among subjects

\begin{tabular}{|l|l|l|l|}
\hline \multicolumn{2}{|c|}{} & Count & $\%$ \\
\hline \multirow{2}{*}{ Outcome of patient } & Death & 6 & $3.0 \%$ \\
\cline { 2 - 4 } & Discharged & 194 & $97.0 \%$ \\
\hline
\end{tabular}

In the study $3 \%$ had mortality and $97 \%$ were discharged.

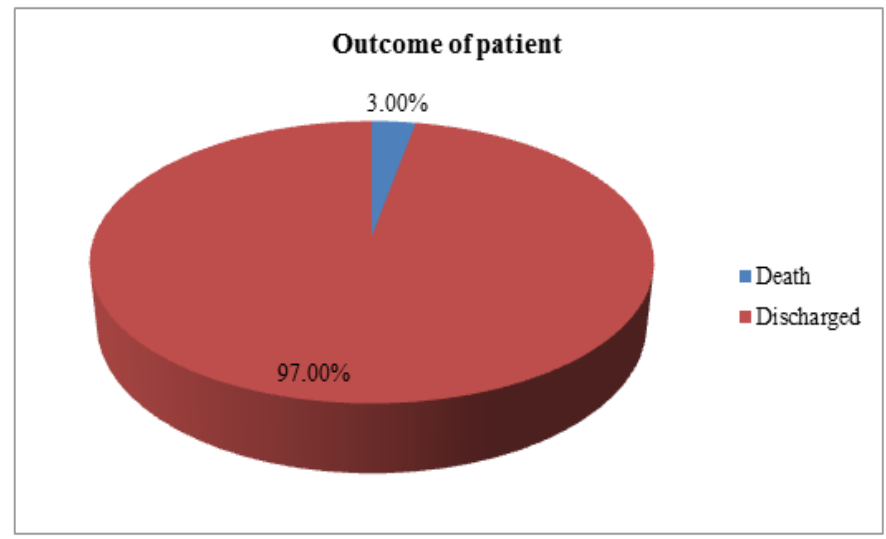

Fig-6: Pie diagram showing Outcome of patient distribution among subjects 
Table-7: Platelet transfusion distribution among subjects

\begin{tabular}{|l|l|l|l|}
\hline \multicolumn{2}{|c|}{} & Count & $\%$ \\
\hline \multirow{2}{*}{ Platelet transfusion } & No & 132 & $66.0 \%$ \\
\cline { 2 - 4 } & Yes & 68 & $34.0 \%$ \\
\hline
\end{tabular}

In the study $34 \%$ had Platelet transfusion.

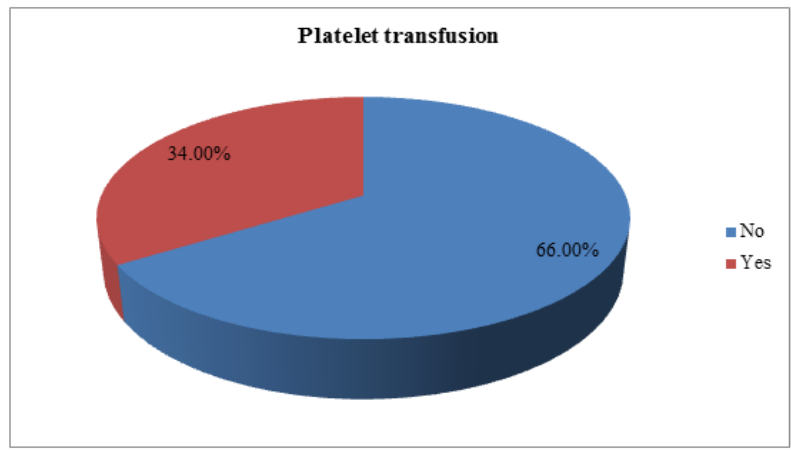

Fig-7: Pie diagram showing Platelet transfusion distribution among subjects

Table-8: Mean distribution of laboratory parameters

\begin{tabular}{|l|l|l|l|l|l|}
\hline & Mean & SD & Median & Minimum & Maximum \\
\hline Haemoglobin & 13.5 & 2.2 & 13.6 & 6.0 & 18.8 \\
\hline Total count & 6218.5 & 8472.5 & 5000.0 & 7.3 & 118000.0 \\
\hline Platelet at admission & 43474.8 & 40870.3 & 31000.0 & 3800.0 & 305000.0 \\
\hline Total bilirubin & 1.0 & 1.2 & 0.7 & 0.1 & 8.8 \\
\hline Direct bilirubin & 0.5 & 0.8 & 0.2 & 0.0 & 6.6 \\
\hline Indirect bilirubin & 1.7 & 16.0 & 0.4 & 0.0 & 203.0 \\
\hline
\end{tabular}

Mean $\mathrm{Hb}$ among subjects was $13.5 \pm 2.2$ $\mathrm{gm} / \mathrm{dl}$. Median total count was 5000.0, median Platelet at admission was 31000.0 , median Total bilirubin was
$0.7 \mathrm{mg} / \mathrm{dl}$, median direct bilirubin was 0.2 and median was 0.4 .

Table-9: Association between platelet transfusion and Dengue serology

\begin{tabular}{|c|c|c|c|c|c|c|}
\hline & \multicolumn{4}{|c|}{ Platelet transfusion } & \multirow[t]{3}{*}{$P$ value } \\
\hline & & \multicolumn{2}{|c|}{ No } & \multicolumn{2}{|l|}{ Yes } & \\
\hline & & Count & $\%$ & Count & $\%$ & \\
\hline \multirow{2}{*}{ NS1 } & Negative & 47 & $35.6 \%$ & 10 & $14.7 \%$ & \multirow[t]{2}{*}{$0.002 *$} \\
\hline & Positive & 85 & $64.4 \%$ & 58 & $85.3 \%$ & \\
\hline \multirow{2}{*}{$\operatorname{IgM}$} & Negative & 96 & $72.7 \%$ & 47 & $69.1 \%$ & \multirow[t]{2}{*}{0.592} \\
\hline & Positive & 36 & $27.3 \%$ & 21 & $30.9 \%$ & \\
\hline \multirow{2}{*}{$\operatorname{IgG}$} & Negative & 93 & $70.5 \%$ & 56 & $82.4 \%$ & \multirow[t]{2}{*}{0.067} \\
\hline & Positive & 39 & $29.5 \%$ & 12 & $17.6 \%$ & \\
\hline
\end{tabular}

In the study among those who received platelet transfusion, NS1 was positive in $85.3 \%$, $\operatorname{IgM}$ in $30.9 \%$,
IgG in $17.6 \%$. There was significant association between NS1 positivity and platelet transfusion.

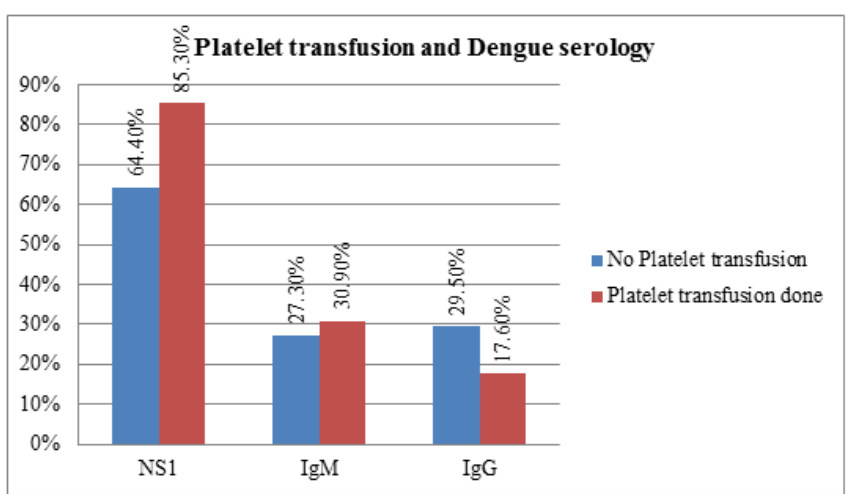

Fig-8: Bar diagram showing Association between platelet transfusion and Dengue serology 
Table-10: Association between bleeding manifstation and Dengue serology

\begin{tabular}{|c|l|l|l|l|l|l|}
\hline \multicolumn{2}{|c|}{} & \multicolumn{3}{|l}{ Bleeding manifestations } & \multirow{2}{*}{ P value } \\
\cline { 3 - 7 } \multicolumn{2}{|c|}{} & No & \multicolumn{3}{l|}{ Yes } & \\
\cline { 2 - 6 } \multicolumn{2}{|c|}{} & Count & $\%$ & Count & $\%$ & \\
\hline \multirow{2}{*}{ NS1 1} & Negative & 48 & $32.2 \%$ & 9 & $17.6 \%$ & \multirow{2}{*}{$0.047 *$} \\
& Positive & 101 & $67.8 \%$ & 42 & $82.4 \%$ & \\
\hline \multirow{2}{*}{ IgM } & Negative & 108 & $72.5 \%$ & 35 & $68.6 \%$ & 0.599 \\
\cline { 2 - 6 } & Positive & 41 & $27.5 \%$ & 16 & $31.4 \%$ & \\
\hline \multirow{2}{*}{ IgG } & Negative & 110 & $73.8 \%$ & 39 & $76.5 \%$ & 0.708 \\
\cline { 2 - 6 } & Positive & 39 & $26.2 \%$ & 12 & $23.5 \%$ & \\
\hline
\end{tabular}

In the study among those with bleeding manifestations, NS1 was positive in $82.4 \%$, IgM in
$31.4 \%$, IgG in $23.5 \%$. There was significant association between NS1 positivity and bleeding manifestations.

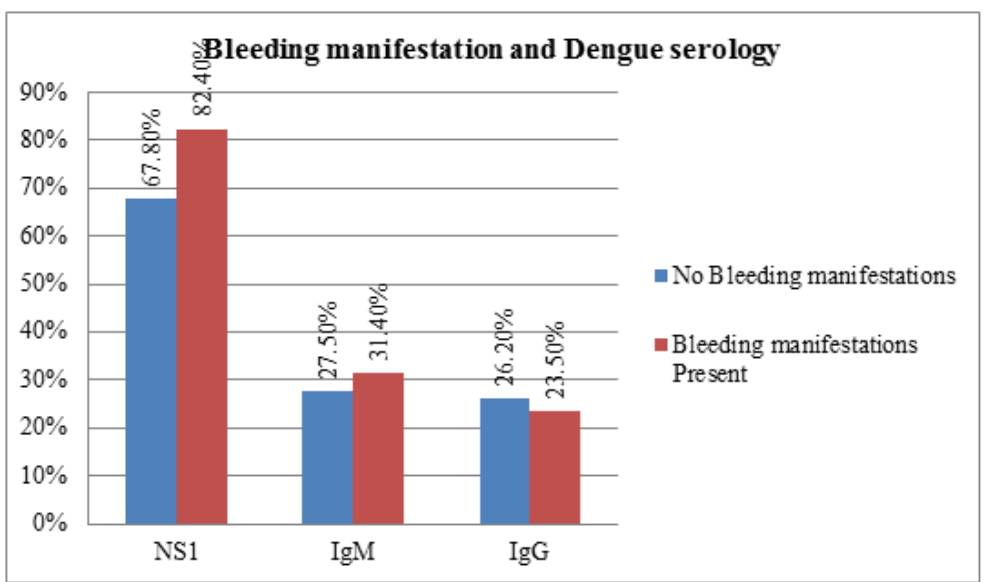

Fig-9: Bar diagram showing Association between platelet transfusion and Dengue serology

Table-11: Dengue serology distribution

\begin{tabular}{|l|l|l|l|}
\hline \multicolumn{2}{|l|}{} & Count & \% \\
\hline \multirow{5}{*}{ Dengue Serology } & IgG & 29 & $14.5 \%$ \\
\cline { 2 - 4 } & IgM & 19 & $9.5 \%$ \\
\cline { 2 - 4 } & IgM+IgG & 9 & $4.5 \%$ \\
\cline { 2 - 4 } & $\mathrm{NS} 1$ & 103 & $51.5 \%$ \\
\cline { 2 - 4 } & $\mathrm{NS} 1+\operatorname{IgG}$ & 11 & $5.5 \%$ \\
\cline { 2 - 4 } & $\mathrm{NS} 1+\mathrm{IgM}$ & 27 & $13.5 \%$ \\
\cline { 2 - 4 } & $\mathrm{NS} 1+\mathrm{IgM}+\mathrm{IgG}$ & 2 & $1.0 \%$ \\
\hline
\end{tabular}

In the study $14.5 \%$ were only IgG positive, $9.5 \%$ were only IgM Positive, $4.5 \%$ were $\operatorname{IgM}+\operatorname{IgG}$ positive, $51.5 \%$ were only NS1 positive, $5.5 \%$ were NS1+IgG positive, $13.5 \%$ were NS1 + IgM positive and $1 \%$ were NS1+IgM+IgG positive.

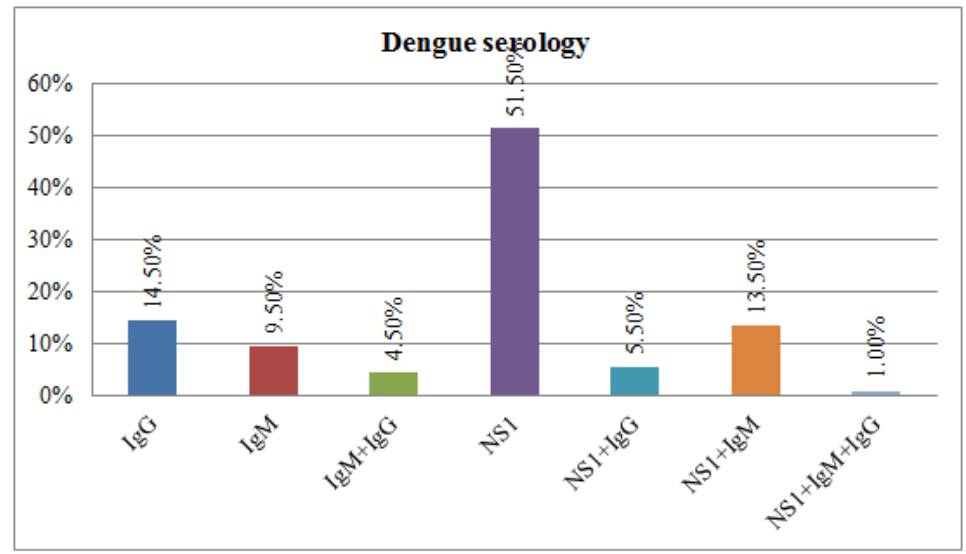

Fig-10: Bar diagram showing Dengue serology distribution 
Table-12: AST and ALT distribution

\begin{tabular}{|l|l|l|l|}
\hline \multicolumn{2}{|c|}{} & Count & Column N \% \\
\hline \multirow{2}{*}{ AST } & Increased & 187 & $93.5 \%$ \\
\cline { 2 - 4 } & Normal & 13 & $6.5 \%$ \\
\hline \multirow{2}{*}{ ALT } & Increased & 156 & $78.0 \%$ \\
\cline { 2 - 4 } & Normal & 44 & $22.0 \%$ \\
\hline
\end{tabular}

In the study $93.5 \%$ had raised AST levels and 78\% had raised ALT levels.

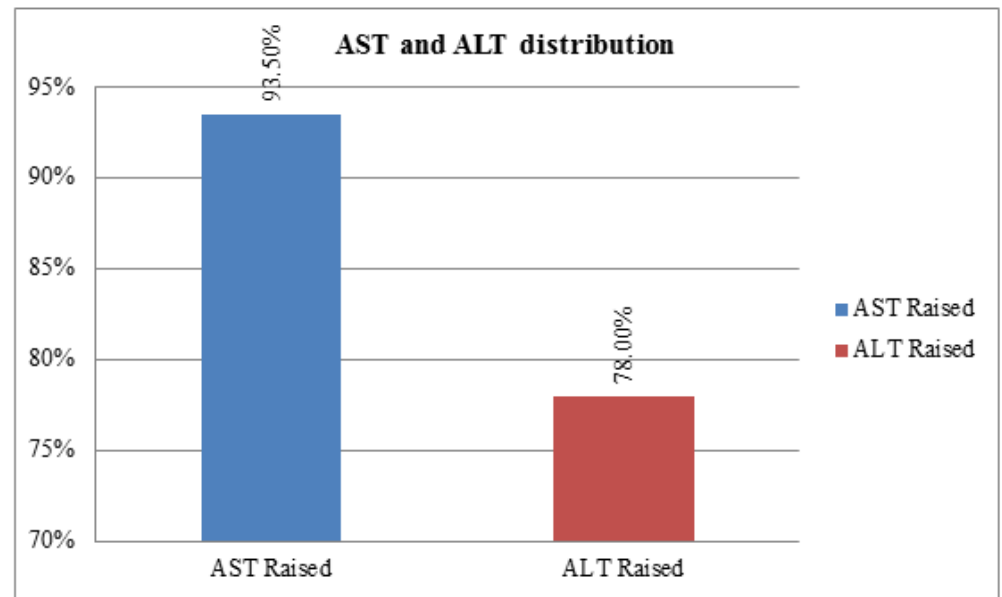

Fig-11: Bar diagram showing AST and ALT distribution

Table-13: Association between AST findings and Dengue serology

\begin{tabular}{|c|l|l|l|l|l|l|}
\hline \multicolumn{2}{|c|}{} & \multicolumn{3}{|l|}{ AST } & \multirow{2}{*}{ P value } \\
\cline { 3 - 6 } \multicolumn{2}{|c|}{} & Increased & \multicolumn{2}{l|}{ Normal } & \\
\cline { 2 - 6 } \multicolumn{2}{|c|}{} & Count & $\%$ & Count & $\%$ & \\
\hline \multirow{2}{*}{ NS1 1} & Negative & 51 & $27.3 \%$ & 6 & $46.2 \%$ & \multirow{2}{*}{0.145} \\
\cline { 2 - 6 } & Positive & 136 & $72.7 \%$ & 7 & $53.8 \%$ & \\
\hline \multirow{2}{*}{ IgM } & Negative & 131 & $70.1 \%$ & 12 & $92.3 \%$ & \multirow{2}{*}{0.086} \\
\cline { 2 - 6 } & Positive & 56 & $29.9 \%$ & 1 & $7.7 \%$ & \\
\hline \multirow{2}{*}{ IgG } & Negative & 141 & $75.4 \%$ & 8 & $61.5 \%$ & \multirow{2}{*}{0.267} \\
\cline { 2 - 6 } & Positive & 46 & $24.6 \%$ & 5 & $38.5 \%$ & \\
\hline
\end{tabular}

In the study there was no significant association between NS1, IgM, IgG with AST levels.

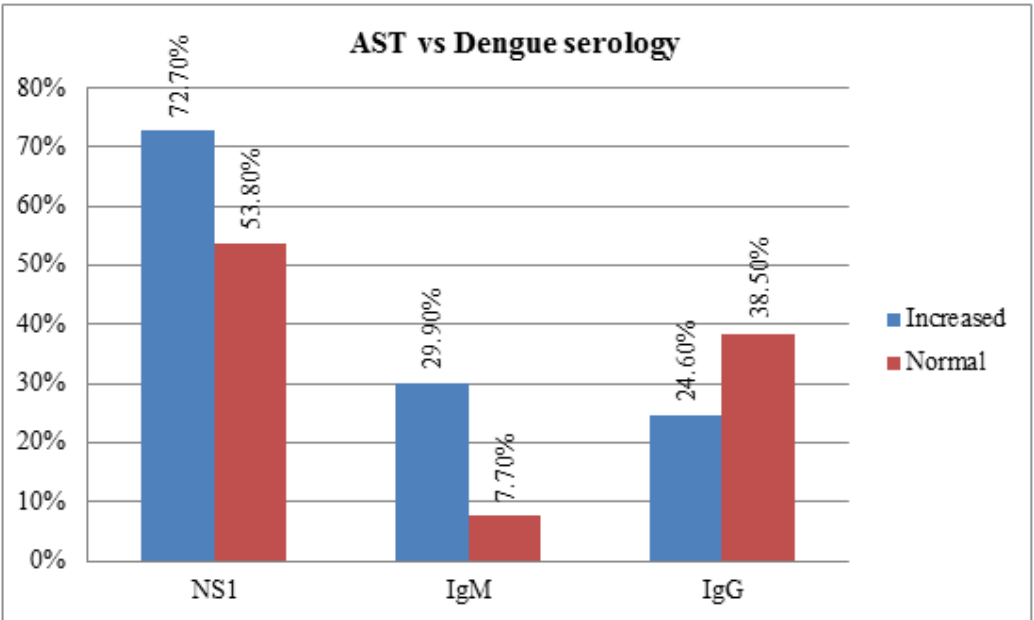

Fig-13: Bar diagram showing Association between AST findings and Dengue serology 
Table-15: Association between AST findings and Dengue serology

\begin{tabular}{|c|l|l|l|l|l|l|}
\hline \multicolumn{2}{|c|}{} & \multicolumn{3}{|l|}{ ALT } & \multirow{2}{*}{ P value } \\
\cline { 3 - 6 } \multicolumn{2}{|c|}{} & Increased & \multicolumn{2}{l|}{ Normal } & \\
\cline { 2 - 6 } \multicolumn{2}{|c|}{} & Count & $\%$ & Count & $\%$ & \\
\hline \multirow{2}{*}{ NS1 1} & Negative & 38 & $24.4 \%$ & 19 & $43.2 \%$ & \multirow{2}{*}{$0.015^{*}$} \\
\cline { 2 - 6 } & Positive & 118 & $75.6 \%$ & 25 & $56.8 \%$ & \\
\hline \multirow{2}{*}{ IgM } & Negative & 110 & $70.5 \%$ & 33 & $75.0 \%$ & \multirow{2}{*}{0.560} \\
\cline { 2 - 6 } & Positive & 46 & $29.5 \%$ & 11 & $25.0 \%$ & \\
\hline \multirow{2}{*}{ IgG } & Negative & 119 & $76.3 \%$ & 30 & $68.2 \%$ & \multirow{2}{*}{0.276} \\
\cline { 2 - 6 } & Positive & 37 & $23.7 \%$ & 14 & $31.8 \%$ & \\
\hline
\end{tabular}

In the study there was significant association between NS1 and ALT levels, among those with raised ALT levels, $75.6 \%$ were positive for NS1.

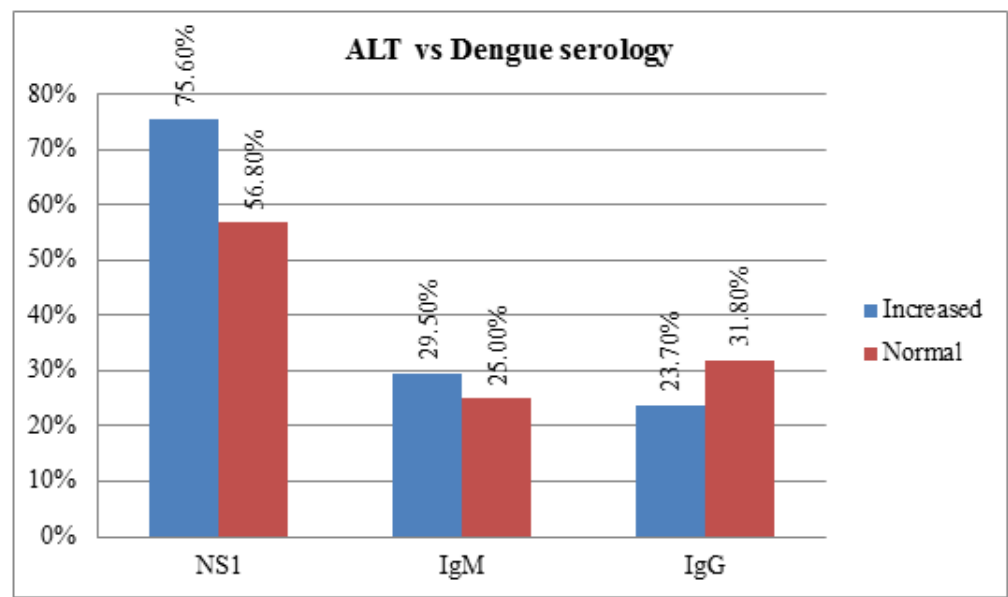

Fig-14: Bar diagram showing Association between AST findings and Dengue serology

\section{DISCUSSION}

Our study showed that out of 200 patients with dengue fever, $58.5 \%$ were male and $41.5 \%$ were female. About $37 \%$ were in the age group of 21 to 30 years with mean age of study group being $33.7 \pm 12.1$ years.

Our study showed varied spectrum of clinical presentation all of them had fever as a symptom at presentation, $44 \%$ of them had generalised body ache, $25.5 \%$ had bleeding manifestations, $24 \%$ had vomiting, $6.5 \%$ has abdominal pain, $6 \%$ had lethargy, $1 \%$ had seizures and $0.5 \%$ had altered sensorium. $13.5 \%$ of the patients had hypotension. $6 \%$ of them had diabetes and $5 \%$ being hypertensives.

In this present study serosities was present in $34.5 \%$ of patients and $30 \%$ had bilateral pleural effusion. In a study done by Mandal et al., ascites was present in $8.1 \%$ and pleural effusion in $18.9 \%$ of cases [6].

In this present study $71.5 \%$ were NS1 positive, $28.5 \%$ were positive for $\operatorname{IgM}$ and $25.5 \%$ were positive for IgG. In northeast India study NS1 was positive in $91.6 \%$ cases, IgM positive in $4.7 \%$ cases and mixed positivity in $3.7 \%$ cases [7].
In our study among those who received platelet transfusion NS1 was positive in $85.3 \%$ and those who had bleeding manifestation NS1 was positive in $82.4 \%$. Study showed significant association between NS1 positivity, bleeding manifestation and platelet transfusion.

In our study there was significant association between NS1 and ALT levels, among those with raised ALT $75.6 \%$ were positive for NS1. Mandal et al. documented elevated transaminases in $83.78 \%$ of cases [6].

Study done by Maimoona M. Ahmed concludes that sequential infection with different dengue virus serotypes, concurrent/sequential infection of more than one serotype and differences in host immune reponses associated with host genetic variations increase the risk of developing dengue haemorrhagic fever. Our study has showed that NS1 positivity was associated with severe form of dengue [8].

This study had mortality rate of $3 \%$. Out of 6 patients who died 4 of them were positive for NS1, 1 patient was positive for IgM and IgG and another being positive for IgG. Among those who died 2 of them NS1 positivity and fulminant hepatitis. 4 of them had 
bleeding manifestation requiring blood transfusion. Study by Gupta et al had mortality rate of 4.14\%[9].

Dengue fever presents with nonspecific symptoms during early phase, which is differentiated from other febrile illness by testing for Dengue profile and if NS1, it cautions the treating physician for close monitoring and follow up of the dengue positive cases for the development of DHF and DSS thereby reducing the complications by early intervention.

\section{Conclusion}

Initial presentation of Dengue fever is very nonspecific and is difficult to differentiate the mild and severe form of the disease. Hence dengue profile is essential for all the suspected cases. If NS1 is positive, complications like DHS and DSS are expected and they are to be closely monitored and managed effectively.

\section{REFERENCES}

1. World Health Organization and Tropical Diseases Research. Dengue: Guidelines for diagnosis, treatment, prevention and control. Geneva: World Health Organization; 2009: new edition.

2. WHO handbook for clinical management of dengue fever
3. Elzinandes Leal de, Robson Q, Luzia Maria. Thrombocyopenia in dengue: Interrelationship between virus and the imbalance between coagulation and fibrinolysis and inflammatory mediators. Hindawi. 2015.

4. Parameswarappa Jyoth, Basavaraj C. Metri. Correlation of serological markers and platelet count in the diagnosis of dengue virus infection. Adv Biomed Res. 2015;4:26.

5. Paranavitane. Dengue NS1 antigen as a marker of severe clinical disease. BMC infectious diseases. 2014; 14:570.

6. Mandal SK, Ganguly J, Sil K, Chatterjee S, Chatterjee K, Sarkar P, Hazra S, Sardar D. Clinical profiles of dengue fever in a teaching hospital of eastern India. Headache. 2013;40:62-16.

7. Bharaj P, Chahar HS, Pandey A, Diddi K, Dar L, Guleria R. Concurrent infections by all four dengue virus serotypes during an outbreak of dengue in 2006 in Delhi, India. Virol J. 2008; 5:1.

8. Maimoona M. Ahmed. Clinical profile of dengue fever infection in King Abdul Aziz Uiversity Hospital Saudi Arabia. J Infect Dev Ctries. 2010; 4(8):503-10.

9. Gupta E, Dar L, Kapoor G, Broor S. "The changing epidemiology of dengue in Delhi, India," virology Journal. 2006;3;92. 